\title{
Long Noncoding RNA HOTAIR Promotes Epithelial-Mesenchymal Transition and Is a Suitable Target to Inhibit Peritoneal Dissemination in Human Scirrhous Gastric Cancers
}

\author{
Yoshifumi Takei $^{\mathrm{a}}$ Toshifumi Hara $^{\mathrm{a}}$ Akiko Suzuki $^{\mathrm{a}}$ b Keichiro Mihara ${ }^{\mathrm{b}}$ \\ Kazuyoshi Yanagiharac \\ a Department of Medicinal Biochemistry, School of Pharmacy, Aichi Gakuin University, Nagoya, Japan; ${ }^{b}$ Department of \\ Hematology and Oncology, Research Institute for Radiation Biology and Medicine, Hiroshima University, Hiroshima, \\ Japan; ' Division of Translational Research, Exploratory Oncology and Clinical Trial Center, National Cancer Center, \\ Kashiwa, Chiba, Japan
}

\section{Keywords}

Scirrhous gastric cancer $\cdot$ Long noncoding RNA · Peritoneal dissemination - Epithelial-mesenchymal transition .

MicroRNA · Antimetastasis therapy · Small interfering

RNA-based medicine

\begin{abstract}
Objectives: Scirrhous gastric cancer, which accounts for approximately $10 \%$ of all gastric cancers, often disseminates to the peritoneum, leading to intractable cases with poor prognosis. There is an urgent need for new treatment approaches for this difficult cancer. Methods: We previously established an original cell line, HSC-60, from a scirrhous gastric cancer patient and isolated a peritoneal-metastatic cell line, $60 \mathrm{As} 6$, in nude mice following orthotopic inoculations. In the present study, we focused on the expression of long noncoding ribonucleic acid (RNA) (IncRNA) in the cell lines and investigated the mechanism on peritoneal dissemination. Results: We demonstrated that an IncRNA, HOX transcript antisense RNA (HOTAIR), is expressed significantly more highly in 60 As 6 than HSC-60 cells. Then, using both HOTAIR knockdown and overexpression experiments, we showed that
\end{abstract}

karger@karger.com

(c) 2020 S. Karger AG, Basel

www.karger.com/pat

Karger" high-level expression of HOTAIR promotes epithelial-mesenchymal transition (EMT) in 60As6 cells. By luciferase assay, we found that HOTAIR directly targets and binds to miR-217, and that miR-217 directly binds to Zinc finger E-box-binding homeobox 1 (ZEB1). The knockdown of HOTAIR in 60As6 cells significantly reduced the invasion activity and peritoneal dissemination - and significantly prolonged the survival - in the orthotopic tumor mouse model. Conclusion: An EMT-associated pathway (the HOTAIR-miR-217-ZEB1 axis) appears to inhibit peritoneal dissemination and could lead to a novel therapeutic strategy against scirrhous gastric cancer in humans.

(c) 2020 S. Karger AG, Basel

\section{Introduction}

Along with the emergence of next-generation DNA sequencers, over $80 \%$ of the human genome has been transcribed [1-3]. Less than $3 \%$ of the human genome produces proteins. The remaining, non-protein-producing RNAs are known as noncoding RNAs (ncRNAs) [3-5], and ncRNAs with $>200$ nucleotides are defined as long 
ncRNAs (lncRNAs) [4, 5]. Over 10,000 lncRNAs have been identified by transcriptomic analysis $[4,5]$. Most of the IncRNAs are transcribed by RNA polymerase II, polyadenylated, and $5^{\prime}$-capped, which is the same sequence of actions applied to protein-coding messenger RNAs (mRNAs). IncRNAs are evolutionarily conserved and have various roles in cellular processes as well as cancer development $[4,5]$. To date, many different types of malignancies have been characterized by dysregulation of $\ln$ cRNAs, prompting several groups to use lncRNAs as diagnostic biomarkers and/or therapeutic targets in various cancers [5-7].

In the present study, we focused on an IncRNA, HOX transcript antisense RNA (HOTAIR), which was first identified in 2007 [8, 9]. HOTAIR is a 2.2 -kb noncoding transcript generated from the HOXC gene cluster located on chromosome 12q13.13 in the human genome, and many studies have reported that elevated HOTAIR expression in cancers is associated with cancer metastasis [10-12]. HOTAIR is also associated with motility, invasion, metastatic potential, and negative prognosis of metastatic melanoma [13], esophageal squamous cell carcinoma [14], breast carcinoma [15], colorectal carcinoma [16], ovarian carcinoma [17], and hepatocellular carcinoma [18]. However, there are few reports on the relationship between HOTAIR and scirrhous gastric cancers including peritoneal dissemination properties. Also, we have almost no knowledge regarding the significance of HOTAIR as a therapeutic target against peritoneal dissemination in scirrhous gastric cancers.

Recently, we have established an experimental model of peritoneal dissemination in scirrhous gastric cancers for both in vitro and in vivo study [19]. Thus, we established a parental cell line of scirrhous gastric cancer from a patient, HSC-60, and a metastatic cell line, $60 \mathrm{As} 6$, which we isolated by repeated cycles of orthotopic inoculation of HSC- 60 cells, collection of ascites fluid, and re-inoculation in nude mice [19].

In this article, we show that HOTAIR expression is higher in the 60 As 6 metastatic cell line than the parental HSC-60 cell line, and the elevated HOTAIR promotes epithelial-mesenchymal transition (EMT) in the 60 As6 cells, allowing them to acquire their peritoneal dissemination properties. In addition, we demonstrate that a small interfering RNA (siRNA)-based therapy targeting HOTAIR inhibits the peritoneal dissemination in our mouse orthotopic model. Finally, we discuss the clinical significance of these findings for patients with scirrhous gastric cancers with peritoneal dissemination.

\section{Materials and Methods}

\section{Cells}

We previously established several original cell lines from patients with human scirrhous gastric cancer as described in earlier studies [19-21]. We used these 2 cell lines for our experiments in the present study: HSC-60 is a parental cell established from a patient, and 60As6 is a metastatic cell isolated from the parental cells through repeated steps of orthotopic inoculation in nude mice, gathering ascites fluids from the mouse, and then re-inoculation on the stomach wall into the other new nude mice [19]. To maintain the cells, we used RPMI 1640 medium with $10 \%$ fetal bovine serum as described previously [19-24]. For control and confirming experiments, we also used our original cell lines (a parental line, HSC-44PE, and a metastatic line, 44As3) [20, 21, 24 ] established from the other patient with human scirrhous gastric cancer.

\section{RNA Isolation}

We isolated total RNA from the cells and tumor tissues of patients using TRIzol ${ }^{\circledR}$ (Invitrogen) as reported previously [22-27]. The total RNA quality was analyzed by using an Agilent 2100 Bioanalyzer (Agilent Technologies) as reported previously [20-27]. The concentration of each total RNA was determined by using a NanoDrop ND-1000 spectrophotometer (Invitrogen).

\section{Real-Time Quantitative PCR to Analyze Expression Levels of} the Desired mRNAs

Total RNA ( $800 \mathrm{ng}$ ) was reverse-transcribed by a high-capacity cDNA reverse transcription kit (Applied Biosystems, Tokyo, Japan), and PCR was performed with a TaqMan probe specific to the desired genes (Applied Biosystems). All reactions were performed according to the instructions from Applied Biosystems. Hypoxanthine guanine phosphoribosyl transferase 1 was used for normalization $[22,24,25]$.

The TaqMan probes used in the study were as follows: human E-cadherin (gene symbol: CDH1; assay ID, Hs01023894_m1), human N-cadherin (gene symbol: CDH2; assay ID, Hs00362037_ $\mathrm{m} 1$ ), human vimentin (gene symbol: VIM; assay ID, Hs00185584_ $\mathrm{m} 1$ ), and human zinc finger E-box binding homeobox (gene symbol: ZEB1; assay ID, Hs01566408_m1).

Real-Time Quantitative PCR for Micro-RNAs and HOTAIR

The expression of the micro-RNAs (miRNAs) was measured by TaqMan micro-RNA assays as reported previously [22-24]. Each total RNA (5-10 ng) was reverse-transcribed with a TaqMan micro-RNA RT kit and TaqMan micro-RNA assay (Applied Biosystems), and the cDNA was analyzed using a specific TaqMan probe (miR-217) and TaqMan Universal PCR Master Mix as described previously [22-24]. The expression level of miRNAs was normalized with small nuclear RNA (RNU6B), and the expression level of HOTAIR was also normalized with glyceraldehyde3-phosphate dehydrogenase.

Preparation of Small Hairpin RNA Stably Expressed Cell Lines from 60 As6 to Knockdown HOTAIR

Cells of a metastatic cell line, 60As6, were transfected with small hairpin RNA (shRNA) lentivector for HOTAIR (Applied Biological Materials Inc., Richmond, Canada), and a stable clone was selected by the puromycin method as described previously [22, 
Table 1. Ascites and peritoneal dissemination of nude mice orthotopically inoculated with scirrhous gastric cancer cells

\begin{tabular}{lllc}
\hline \multirow{2}{*}{$\begin{array}{l}\text { Types of cells } \\
\text { inoculated }\end{array}$} & $\begin{array}{l}\text { Ascites } \\
\text { volume, } \mathrm{mL}\end{array}$ & \multicolumn{2}{l}{ Peritoneal dissemination } \\
\cline { 3 - 4 } & & omentum & mesenterium \\
\hline HSC-60 & $0.4 \pm 0.3$ & $3 / 15$ & $2 / 15$ \\
60As6 & $4.6 \pm 1.4$ & $15 / 15$ & $15 / 15$ \\
60As6-control shRNA & $4.3 \pm 1.1$ & $15 / 15$ & $14 / 15$ \\
60As6-HOTAIR shRNA & $0.9 \pm 0.7^{* *}$ & $4 / 15$ & $3 / 15$ \\
\hline
\end{tabular}

In each group, 15 mice were examined. ${ }^{* *} p<0.01$ versus 60 As6-control shRNA.

24]. Thus, the transfected cells were selected with geneticin (150 $\mu \mathrm{g} / \mathrm{mL}$ ) to obtain a stable HOTAIR knockdown clone (60As6-HOTAIR shRNA).

\section{Preparation of HOTAIR-Overexpressed Cell Lines from HSC-} 60

Cells of the parental line HSC-60 were transfected with a HOTAIR Lentiviral Vector System (Applied Biological Materials Inc., Richmond, Canada), and a stable clone was selected by the puromycin method as described previously $[22,24]$. Thus, the transfected cells were selected with geneticin $(150 \mu \mathrm{g} / \mathrm{mL})$ to obtain a stable HOTAIR overexpression clone (HSC-60-HOTAIR vector).

\section{Preparation of miR-217 Stably Overexpressed Cell Lines from}

60 As6

Cells of the metastatic line 60As6 were transfected with miR217 expression vector ( $1 \mu \mathrm{g}$; Takara Bio, Japan) using a Lipofectamine ${ }^{\circledR} 2000$ reagent (Invitrogen) as reported previously [22, 24]. The transfected cells were selected with geneticin to obtain a stable overexpressing clone (60As6-miR-217). The concentration of geneticin was $150 \mu \mathrm{g} / \mathrm{mL}$.

\section{Invasion Analysis}

The various cell lines were subjected to invasion assay. For this purpose, we used a BD BioCoat Fluoroblok Tumor Invasion System (BD Biosciences) as reported previously [22-24].

In vivo Examination of Ascites, Peritoneal Dissemination, and Survival Rate in Nude Mice

The animal experiments in this study were performed in compliance with the guidelines of the Institute for Laboratory Animal Research, Nagoya University Graduate School of Medicine, Aichi Gakuin University, or the National Cancer Center Research Institute. The cells (HSC-60, 60As6, 60As6-control shRNA, and 60As6HOTAIR shRNA; Tables 1,2$)$ were orthotopically inoculated into the stomach wall in male BALB/c nude mice (6 weeks old; Japan SLC, Hamamatsu, Japan) as reported previously [22, 24]. The total cell number $\left(1.0 \times 10^{6}\right.$ cells in $50 \mu \mathrm{L}$ of RPMI 1640 medium without fetal bovine serum) was inoculated. A 29-gauge needle was used for the injection. Twenty-five days later, the volume of ascites fluid and peritoneal dissemination (omentum and mesenterium) were investigated. The survival of each mouse in days was determined.

Long Noncoding RNA HOTAIR and

Epithelial-Mesenchymal Transition
Table 2. Survival days of the nude mice orthotopically inoculated with scirrhous gastric cancer cells

\begin{tabular}{ll}
\hline Types of cells inoculated & $\begin{array}{l}\text { Survival days of the } \\
\text { inoculated mice }\end{array}$ \\
\hline HSC-60 & $104 \pm 15$ \\
60As6 & $28 \pm 9$ \\
60As6-control shRNA & $35 \pm 11$ \\
60As6-HOTAIR shRNA & $79 \pm 18^{* *}$ \\
\hline
\end{tabular}

In each group, 15 mice were examined. ${ }^{* *} p<0.01$ versus 60 As6control shRNA.

\section{Dual Luciferase Assay}

The various cells for examination were transiently transfected with pGL3 vector (200 ng, Promega) containing the $3^{\prime}$-untranslated region (UTR) of ZEB1 or the $3^{\prime}$-UTR of ZEB1 with mutation. The specific base sequences of the inserted oligonucleotides are shown in online supplementary Figure 1 (for all online suppl. material, see www.karger.com/doi/10.1159/000508350). pGL3 vector expresses firefly luciferase. The other vector, pRL-TK (50 ng, Promega), expressing Renilla luciferase was also cotransfected. Lipofectamine 2000 (Invitrogen) was used as a transfection reagent. Forty-eight hours after the cotransfection, the cell lysates were prepared, and the firefly and Renilla luciferase activities were measured using dual luciferase assays (Promega) [22-24]. The values of each promoter activity (firefly luciferase activity) were calculated as arbitrary units internally normalized with a Renilla luciferase reporter activity as reported previously [22-24].

\section{Immunostaining}

The procedures were previously reported [22]. The cells for examination were seeded onto Nunc ${ }^{\mathrm{TM}} \mathrm{Lab}^{-\mathrm{Tec}^{\mathrm{TM}}}$ chamber slides (8well and glass type; Nunc) and incubated overnight. The cells were fixed with $4 \%$ paraformaldehyde in PBS for $10 \mathrm{~min}$. After washing, the cells were permeabilized with $0.1 \%$ Triton X-100 in PBS for 20 min, and then the cells were blocked with 3\% bovine serum albumin for $2 \mathrm{~h}$. Primary antibodies from Cell Signaling Japan (Tokyo) against human E-cadherin, $\mathrm{N}$-cadherin, and vimentin were used. The appropriate secondary antibodies, such as Alexa-488-conjugated goat anti-rabbit IgG or Alexa-555-conjugated goat anti-rabbit IgG (Molecular Probes), were also used. All photographs of the stained cells were taken using a confocal microscope system (Nikon A1 Rsi; Nikon, Tokyo, Japan) as reported previously [22].

\section{Antiperitoneal Metastasis Therapy with siRNA-Based}

Medicines

The 60 As 6 cells without any transfection of shRNAs were orthotopically inoculated into the stomach wall of nude mice. Fifteen days later, the therapy was started. Synthetic siRNAs targeting HOTAIR were purchased from Applied Biological Materials (Richmond, Canada). Intravenous injections of each synthetic siRNA (control siRNA or HOTAIR siRNA) were performed on days 0,1 , and 2 . All of the synthetic siRNAs ( $50 \mu \mathrm{g} / \mathrm{shot})$ precomplexed with atelocollagen (Koken, Tokyo, Japan: final concentration, $0.05 \%$ ) were injected into the tail vein of the tumor-bearing 
mice. The set of 3 intravenous injections was repeated on days 10 , 11 , and 12. In each therapy group, 15 mice were examined. On day 15 , all mice were sacrificed, and the primary tumor tissues were excised. Using total RNA isolated from the primary tumor tissues, real-time quantitative PCR (RT-qPCR) for HOTAIR, miR-217, ZEB1, E-cadherin, N-cadherin, and vimentin was performed. On day 15 (the day of sacrifice), the volume of ascites fluid of the treated mice was measured. Peritoneal dissemination was also examined.

\section{Clinical Samples}

The studies of clinical samples were conducted with Institutional Review Board approval from Nagoya University School of Medicine, Aichi Gakuin University, and the National Cancer Center Research Institute. After obtaining appropriate informed consent from each gastric cancer patient, in accordance with the Declaration of Helsinki, cancer tissues (both gastric primary cancer tissues and their peritoneal disseminated cancer tissues from the patients) were harvested. The detailed methods of cancer tissue frozen and RNA extraction are shown in our previous article [24]. Normal stomach tissues were purchased from the BioChain Institute. Each total RNA was extracted from the tissues, and RT-qPCR for HOTAIR, miR-217, and ZEB1 was performed.

\section{Statistical Analysis}

The statistical significance was examined by the Mann-Whitney $U$ test (nonparametric analysis). $p$ values $<0.05$ were accepted as significant.

\section{Results}

HOTAIR Was Expressed at Significantly High Levels in a Metastatic Cell Line, 60As6

According to our global gene expression analysis (SurePrint G3 Human GE Microarray 8x60K version 2, Agilent Technology), we have found that high HOTAIR expression in 60As6 (a metastatic line) was marked compared with a parental line, HSC-60 (online suppl. Table 1). In the table, we showed the altered lncRNAs (top 5 upregulated ones and top 5 downregulated ones) in 60As6; however, the expression levels of the other lncRNAs did not change so much (online suppl. Table 1), suggesting high expression of HOTAIR must affect the peritoneal dissemination property. We also suggested our metastatic model (a parental line, HSC-60; and a metastatic line 60As6) will be beneficial to vigorously explore a novel function(s) of HOTAIR.

We showed by RT-qPCR that the level of HOTAIR expression was significantly higher in 60As6 cells $(p<$ 0.001) than cells of the parental line HSC-60 (Fig. 1). This discovery prompted us to explore the biological significance of HOTAIR in scirrhous gastric cancer and its peritoneal metastasis.

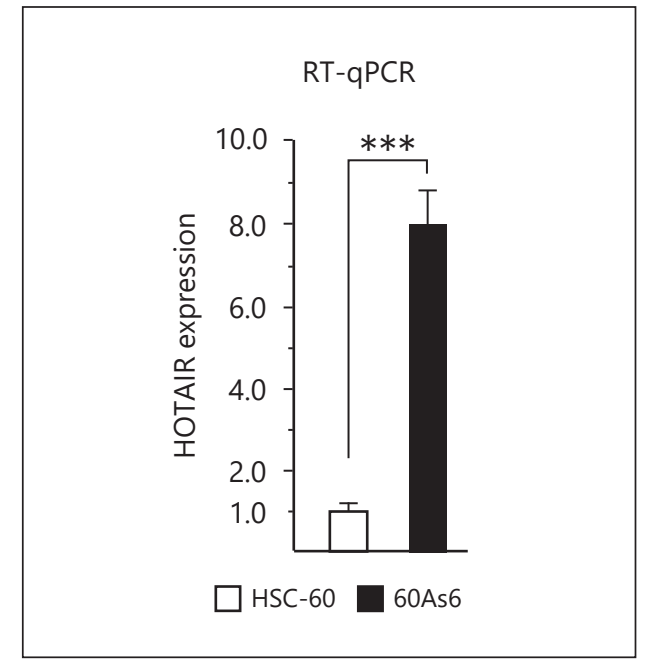

Fig. 1. RT-qPCR analysis of HOTAIR in human scirrhous gastric cancer cell lines HSC-60 and 60As6. White bar, HSC-60; black bar, 60 As6. The results are means \pm SD ( $n=6$ dishes). ${ }^{* * *} p<0.001$.

\section{E-Cadherin Was Significantly Decreased, and $\mathrm{N}$-Cadherin and Vimentin Significantly Increased, in 60 As6 Cells}

We designed various experiments to explore the biological significance of HOTAIR in cancer metastasis and concluded that high levels of HOTAIR promoted EMT in our cancer dissemination model. Immunostaining with a specific antibody showed that, in the metastatic cell line 60 As6, E-cadherin staining was very weak (Fig. 2a). In contrast, strong positive immunostainings of $\mathrm{N}$-cadherin and vimentin were observed in 60As6 cells (Fig. 2a). In HSC-60 cells, the level of E-cadherin was high, and the levels of N-cadherin and vimentin were low (Fig. 2a). Further, RT-qPCR analysis using TaqMan specific probes showed results consistent with the immunostainings (Fig. 2b). Collectively, these results indicated that, in our metastatic model (HSC-60 and 60As6), the parental cell line HSC-60 harbors an epithelial property, and the metastatic line 60As6 harbors a mesenchymal one.

Similar results were obtained in the other established cell lines of ours (a parental line, HSC-44PE, and a metastatic line, 44As3) as shown in online supplementary Figure 2. In the figure, we showed high expression of HOTAIR in 44As3 compared with HSC-44PE. Further, in 44As3, we showed the promotion of EMT (online suppl. Fig. 2).

\section{Preparation of a Stable HOTAIR Knockdown Line in 60 As6 Cells via shRNA}

To investigate the relationship between EMT progression and HOTAIR overexpression in scirrhous gastric 
Fig. 2. Immunostaining and RT-qPCR analysis of human scirrhous gastric cancer cell lines HSC-60 and 60As6. a Immunostaining of E-cadherin, $\mathrm{N}$-cadherin, and vimentin of the cells. E-cadherin was stained with green fluorescence. $\mathrm{N}$-cadherin and vimentin were stained with red fluorescence. Bar, $50 \mu \mathrm{m}$. b RT-qPCR analysis of E-cadherin, N-cadherin, and vimentin. White bars, HSC-60; black bars, 60As6. The results are means $\pm \mathrm{SD}(n=6$ dishes). $* * * p<0.001$.

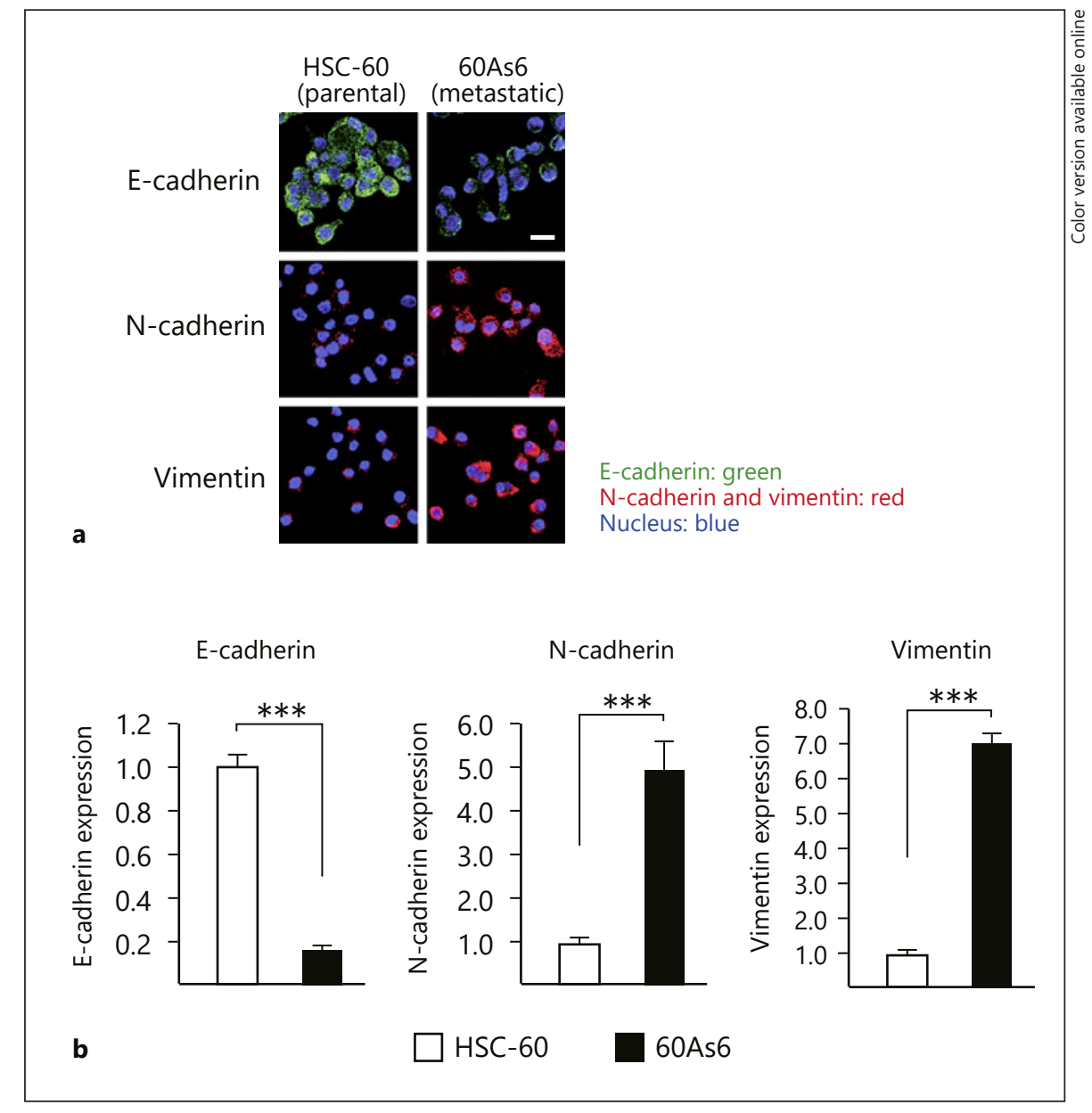

cancers, we newly prepared a stable HOTAIR knockdown line from the 60As6 cells, which we designated 60As6-HOTAIR shRNA (Fig. 3a). Thus, we transfected an shRNA lentivector (Applied Biological Materials, Richmond, Canada) into 60As6 and selected a stable clone by the puromycin method. As a control, a control shRNA lentivector (Applied Biological Materials) was transfected into 60As6 cells. Detailed information on these vectors is available at the following URL: https:// www.abmgood.com/HOTAIR-shRNA-Lentivectorsi009919.html.

RT-qPCR analysis revealed that our preparation of a stable HOTAIR knockdown line in 60As6 cells was successful (Fig. 3a).

\section{The Stable HOTAIR Knockdown Line in 60As6 Cells}

Reversed EMT Progression

Phenotypes of the stable HOTAIR knockdown line in 60As6 cells (60As6-HOTAIR shRNA) were investigated, revealing that HOTAIR knockdown recovered the epithelial property (Fig. 3b). Thus, in the 60As6-HOTAIR shRNA cells, the expression level of E-cadherin was significantly increased $(p<0.001)$. On the other hand, the expression levels of $\mathrm{N}$-cadherin and vimentin were significantly reduced in these knockdown cells $(p<0.01)$. Further, colony formation ability was significantly decreased in the cells (Fig. 3c), and invasion activity was also significantly reduced (Fig. $3 \mathrm{~d}$ ).

\section{Preparation of a Stable HOTAIR-Overexpressing Cell Line in HSC-60 Cells}

We also established a stable HOTAIR-overexpressing cell line in HSC-60 cells for use in control experiments. We transfected a HOTAIR expression vector (Applied Biological Materials, Richmond, Canada) into HSC-60 cells and then selected the stable clone with the reagent geneticin. As a control, an empty vector was transfected. RT-qPCR analysis confirmed that the de- 
Fig. 3. Effect of HOTAIR knockdown on EMT markers, colony formation, and the invasion property. a Preparation of stable HOTAIR knockdown 60 As6 cells via specific shRNA vector transfection. As a starting material, 60As6 cells were used and transfected with an shRNA vector to knockdown HOTAIR expression. After the transfection, positive clones were selected using puromycin. RT-qPCR analysis for HOTAIR was performed. The results are means $\pm \mathrm{SD}$ ( $n=6$ dishes). ${ }^{* * *} p<0.001$. The names of the 4 kinds of samples are shown in the figure. $\mathbf{b}$ RT-qPCR analysis of E-cadherin, N-cadherin, and vimentin. The results are means $\pm \mathrm{SD}$ ( $n=6$ dishes). *** $p<0.001$; ** $p<0.01$. c Colony formation assay. The results are means $\pm \mathrm{SD}(n=$ 6 dishes). ${ }^{* *} p<0.01$. d Invasion analysis. The results are means \pm SD $(n=6$ dishes $)$. *** $p<0.001$.
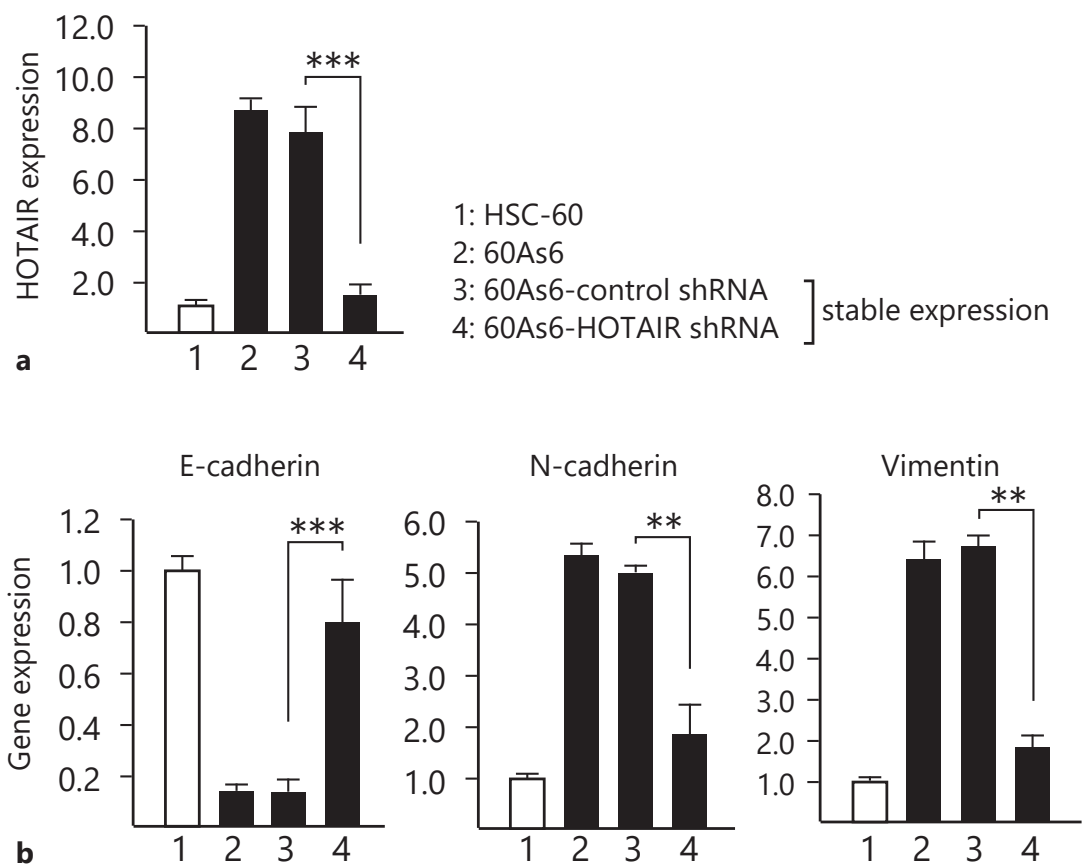

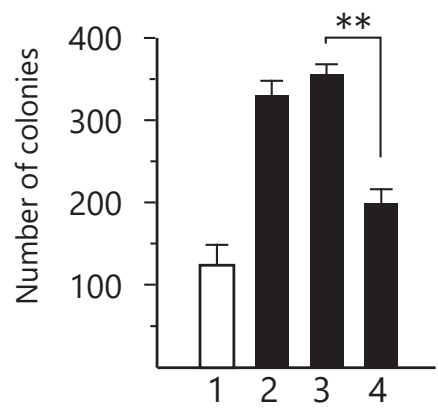

C

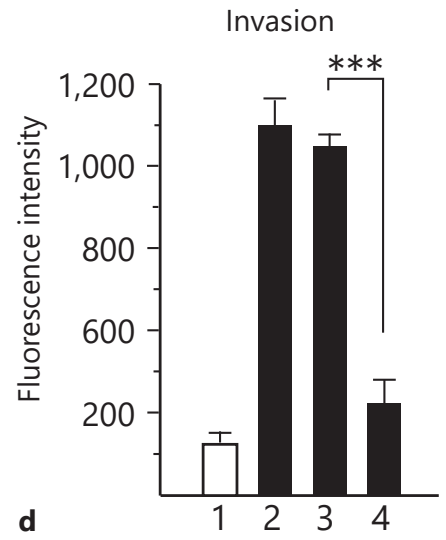

d sired cell line, which we designated stable HOTAIR overexpression line HSC-60, was successfully prepared (Fig. 4a).

\section{The Stable HOTAIR-Overexpressing Cell Line in HSC-} 60 Cells Promoted EMT

Next, we used the stable HOTAIR overexpression line HSC-60 to examine the EMT status. The cells revealed a significantly low expression level of E-cadherin and significantly high expression levels of $\mathrm{N}$-cadherin and vimentin ( $p<0.01$; Fig. $4 \mathrm{~b}$ ). These results clearly indicated that HOTAIR promotes EMT in scirrhous gastric cancers. Colony formation was significantly increased in the cells ( $p<0.01$; Fig. 4 c), and invasion ability was also upregulated ( $p<0.001$; Fig. 4 d).

Similar results were obtained in the other established cell line of ours, HSC-44PE (online suppl. Fig. 3). HSC$44 \mathrm{PE}$ cells significantly showed low expression of HOTAIR, and then we were prompted to prepare a stable HOTAIR overexpression line derived from HSC-44PE. The stable HOTAIR-overexpressing cell line in HSC$44 \mathrm{PE}$ promoted EMT (online suppl. Fig. 3 ). In the stable 
Fig. 4. Overexpression study of HOTAIR in HSC-60. a Preparation of stable HOTAIR-overexpressing HSC-60 cells via transfection of a specific expression vector. As a starting material, HSC-60 cells were used. After the transfection, positive clones were selected using geneticin. RT-qPCR analysis for HOTAIR was performed. The results are means $\pm \mathrm{SD}$ ( $n=6$ dishes). *** $p<0.001$. The names of the 4 kinds of samples are shown in the figure. $\mathbf{b}$ RT-qP$\mathrm{CR}$ analysis of E-cadherin, N-cadherin, and vimentin. The results are means \pm SD ( $n=6$ dishes). ${ }^{* *} p<0.01$. c Colony formation assay. The results are means $\pm \mathrm{SD}(n=$ 6 dishes). ${ }^{* *} p<0.01$. d Invasion analysis. The results are means \pm SD $(n=6$ dishes). *** $p<0.001$.
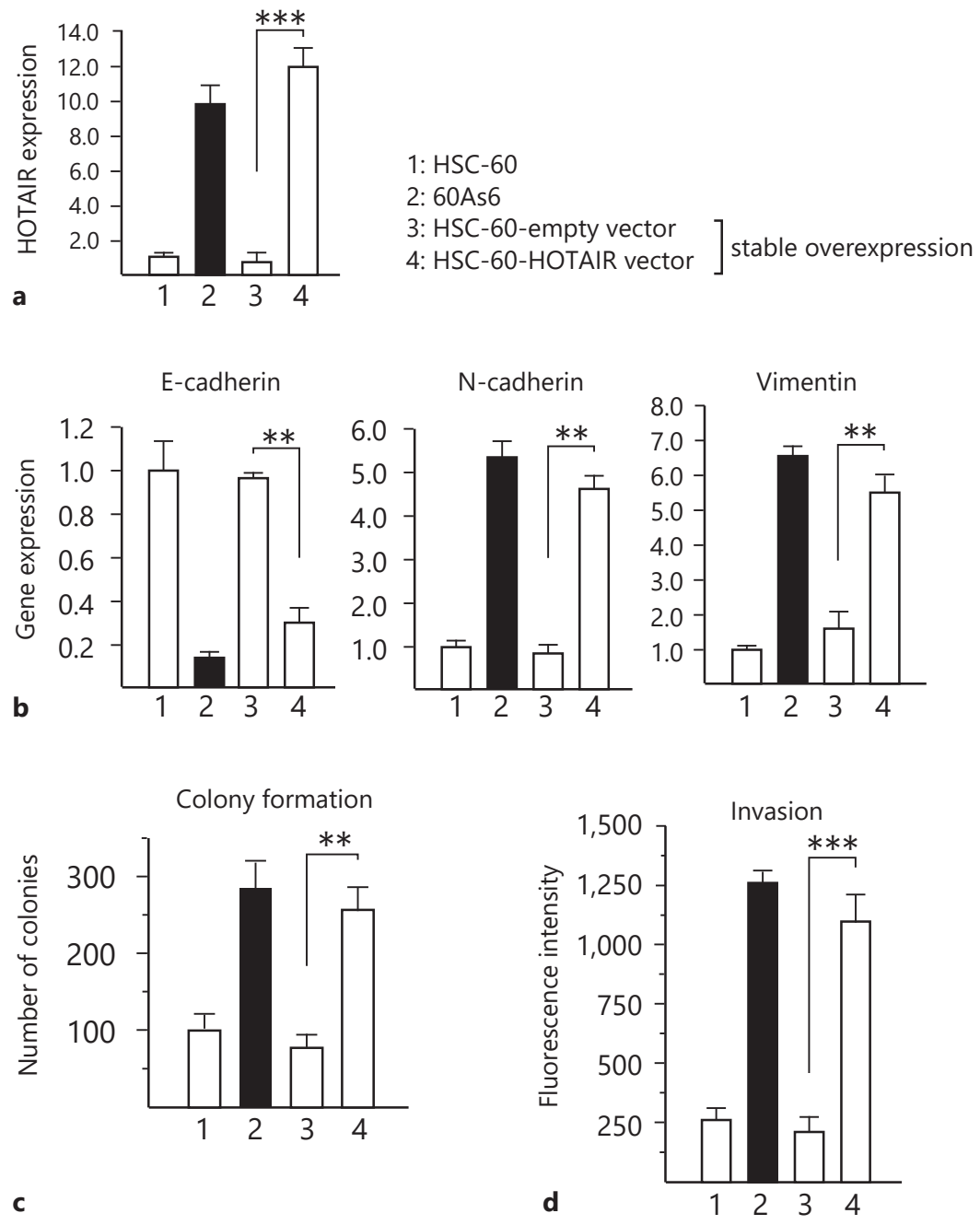

line, both colony formation and invasion ability were significantly upregulated (online suppl. Fig. 3).

\section{HOTAIR Targets miR-217 via Direct Binding}

When we used the stable HOTAIR knockdown line in 60As6 via shRNA, we found that HOTAIR knockdown led to a significant upregulation of miR-217 expression via RT-PCR analysis ( $p<0.001$; Fig. 5a) compared with the control shRNA. Using luciferase assay and transfection of miR-217 mimics into 60As6, we showed that HOTAIR bound directly to miR-217 (online suppl. Fig. 1, 5b). On the other hand, HOTAIR with mutation on the putative binding site did not bind to miR-217 (Fig. 5b).

Long Noncoding RNA HOTAIR and Epithelial-Mesenchymal Transition
miR-217 Directly Targets ZEB1

To investigate the region downstream of miR-217, we successfully prepared a stably and ectopically miR217-overexpressing line in 60As6 cells (termed 60As6miR-217; Fig. 6a). RT-PCR analysis confirmed that this cell line significantly overexpressed miR-217 $(p<0.001$; Fig. 6a) compared with empty vector. Using a luciferase assay, we showed that miR-217 directly and specifically targeted and bound ZEB1 ( $p<0.01$; Fig. $6 \mathrm{~b})$. An RT-PCR analysis specific to ZEB1 demonstrated that ectopic overexpression of miR-217 in 60As6 significantly inhibited the expression of ZEB1 ( $p<0.001$; Fig. $6 c)$.

Overall, in 60As6, we found that an increase in HOTAIR led to a reduction in miR-217, and then miR-217 
Fig. 5. HOTAIR directly targeted miR-217. a The expression level of miR-217 via RTqPCR analysis. The names of the 4 kinds of samples are shown in the figure. The results are means $\pm \operatorname{SD}$ ( $n=6$ dishes). ${ }^{* * *} p<0.001$. b Luciferase reporter assay. After transient transfection of control miRNA (black bars) or miR-217 mimics (white bars) into 60As6 cells, each cell was transfected with the expression plasmid of wild-type HOTAIR or mutant HOTAIR. Two days later, each cell lysate was evaluated via a dual-luciferase assay. The results are means $\pm \mathrm{SD}(n=6$ wells). ${ }^{* *} p<0.01$.

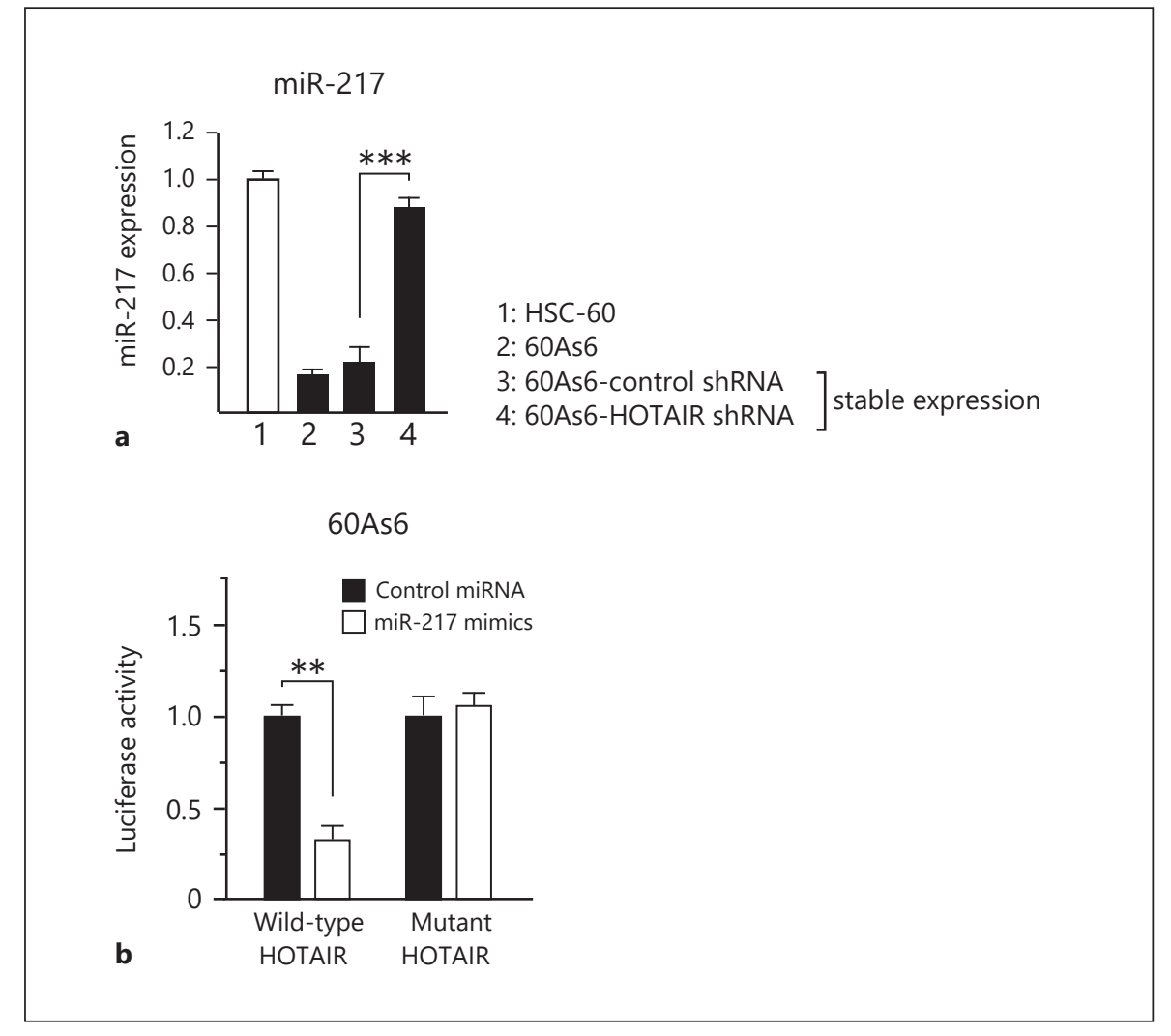

reduction led to an increase in ZEB1 (Fig. 7a, b). Increased levels of ZEB1 promote EMT, as described by us and others [22, 28-30].

\section{In vivo Phenotypes}

To investigate the in vivo phenotypes of the stable knockdown of HOTAIR in 60As6, we performed the orthotopic inoculation of 60As6-HOTAIR shRNA into the stomach wall of nude mice (Table 1 ). In the mice, 15 days after the orthotopic inoculation, the volume of pooled ascitic fluid was dramatically and significantly reduced compared with that in the mice inoculated with 60As6control shRNA ( $p<0.01$; Table 1). Regarding peritoneal dissemination (omentum and mesenterium), we showed a dramatic reduction in the mice inoculated with 60As6HOTAIR shRNA (Table 1). The mice inoculated with 60As6-HOTAIR shRNA lived for a significantly longer amount of time compared with the mice inoculated with 60As6-control shRNA $(p<0.01$; Table 2).

Using the other established cell lines of ours (a parental line, HSC-44PE, and a metastatic line, 44As3), we confirmed the in vivo phenotypes (ascites and peritoneal dissemination). As shown in online supplementary Table 2, the orthotopic inoculation of 44As3-HOTAIR shRNA cells (a stable HOTAIR knockdown line derived from $44 \mathrm{As} 3$ ) in nude mice showed the significant reduction of the volumes of ascites. Further, peritoneal dissemination was inhibited (online suppl. Table 2).

\section{Proposal of Antiperitoneal Dissemination Therapy Targeting HOTAIR}

We used our orthotopic tumor model of nude mice to evaluate whether HOTAIR can be targeted to inhibit peritoneal dissemination. First, we orthotopically inoculated 60 As 6 cells on the stomach wall of nude mice. After the formation of primary tumors at the stomach wall (15 days after inoculation), we intravenously injected siRNA against HOTAIR through the tailvein of the mice (Fig. 8a). For tumor-specific delivery of HOTAIR siRNA via a systemic route, we used a biomaterial, atelocollagen [22-27, $31,32]$. Atelocollagen is unique in that it forms a complex with nucleic acid molecules such as siRNA, miRNA, or plasmid vectors to increase their stability in the living body, and to specifically deliver them into tumor tissues. As shown in Figure 8a, on day 15 after the first injection of the siRNA/atelocollagen complex, HOTAIR expression was significantly decreased in the orthotopic 60As6 tumors via RT-qPCR $(p<0.001$; Fig. $8 \mathrm{~b})$ compared with 
Fig. 6. miR-217 directly targeted ZEB1. a Preparation of stably overexpressed 60 As 6 cells of miR-217 via transfection of a specific expression vector. As a starting material, 60As6 cells were used. After the transfection, positive clones were selected using geneticin. RT-qPCR analysis for miR-217 was performed. The results are means $\pm \mathrm{SD}$ ( $n=6$ dishes). ${ }^{* * *} p<0.001$. The names of the 4 kinds of samples are shown in the figure. $\mathbf{b}$ Luciferase reporter assay. The cells (60As6-miR-217) from a were transfected with pGL3 vector alone (mock), pGL3-ZEB1-3'-UTR (MUT), or pGL3-ZEB1-3'-UTR as indicated. Two days later, each cell lysate was examined via dual-luciferase assay. The results are means $\pm \mathrm{SD}$ ( $n=6$ wells). ${ }^{* *} p<0.01$. c RT-qPCR analysis of ZEB1. The results are means \pm $\mathrm{SD}\left(n=6\right.$ dishes). ${ }^{* * *} p<0.001$.

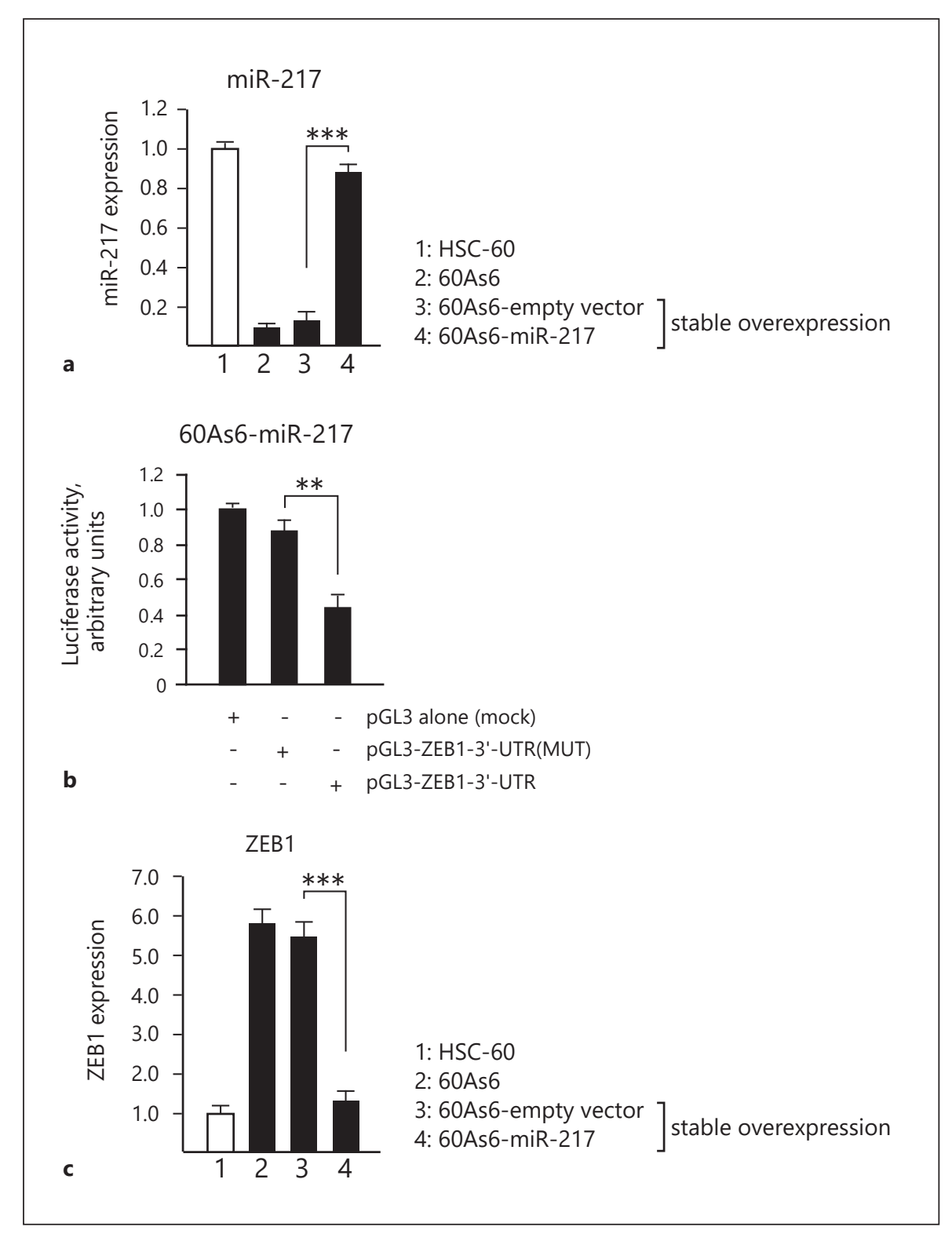

control siRNA/atelocollagen complex. The expression level of miR-217 in the tumors was significantly increased $(p<0.001)$, and that of ZEB1 was significantly reduced ( $p$ $<0.01$; Fig. 8b). Regarding EMT markers in the treated tumors, the expression level of E-cadherin was significantly increased, and $\mathrm{N}$-cadherin and vimentin were significantly decreased ( $p<0.01 ;$ Fig. $8 c)$. In the treated mice, the volume of the pooled ascitic fluid was significantly smaller than that in the controls $(p<0.01$; Fig. $8 \mathrm{~d})$. Finally, in the treated mice, peritoneal dissemination, such as metastasis to the omentum or mesenterium, was dramatically inhibited (Fig. 8e).

Long Noncoding RNA HOTAIR and Epithelial-Mesenchymal Transition
In the therapy experiments using the other metastatic cells 44As3, we obtained similar results (online suppl. Fig. 4). The intravenous injections of the siRNA/atelocollagen complex against HOTAIR toward the mice with orthotopic tumors derived from 44As3 led to decreased HOTAIR, increased miR-217, and decreased ZEB1. Further in the treated mice, EMT promotion was significantly inhibited (online suppl. Fig. 4). In other words, EMT was induced in them. In the treated mice, both ascitic fluid and peritoneal dissemination were significantly reduced (online suppl. Fig. 4). 
Fig. 7. HOTAIR regulates $Z E B 1$ via miR217. a RT-qPCR analysis of ZEB1. The results are means $\pm \mathrm{SD}$ ( $n=6$ dishes). ${ }^{* *} p<$ 0.01 . The names of the 4 kinds of samples are shown in the figure. $\mathbf{b}$ Schema of our results from HOTAIR to ZEB1 (EMT promotion).

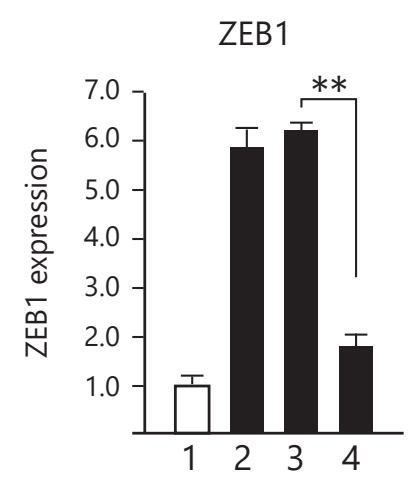

Direction of signal transduction

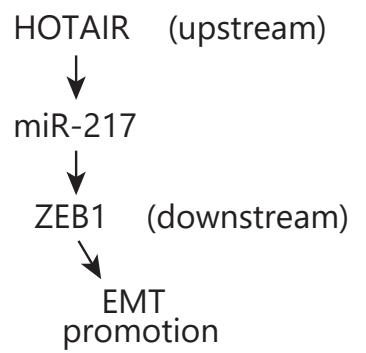

1: HSC-60

2: 60 As6

3: 60As6-control shRNA 1 i: 60As6-HOTAIR shRNA $]$ stable expression

a

b
Table 3. Significantly prolonged survival days of antiperitoneal dissemination therapy with siRNA-based medicines against HOTAIR

\begin{tabular}{ll}
\hline siRNA-based medicines & Survival days of the treated mice \\
\hline Control siRNA & $36 \pm 9$ \\
HOTAIR siRNA & $73 \pm 13^{* *}$
\end{tabular}
siRNA.

Each therapy group included 15 mice. ${ }^{* *} p<0.01$ versus control

\section{HOTAIR-miR-217-ZEB1 Expression Levels in Cancer}

Tissues from Patients

The expression level of HOTAIR in primary gastric cancer tissues from the patients with peritoneal dissemination (Fig. 9a, third column) was significantly increased compared with that of patients without peritoneal dissemination (Fig. 9a, second column; $p<0.01$ ). In stomach tissues from normal donors (Fig. 9a, first column), a very low expression level of HOTAIR was observed. The HOTAIR expression in the peritoneal disseminated cancer tissues was further increased (Fig. 9a, fourth black column). In contrast, the miR-217 expression level (Fig. 9b) was significantly low in the primary gastric cancer tissues from the patients with peritoneal dissemination $(p<$ 0.01 ), and the level was further decreased in the peritoneal disseminated cancer tissues (Fig. 9b). Finally, in concert with the low expression of miR-217, we observed a significantly high expression level of ZEB1 in the patients $(p<0.01$; Fig. 9c). The ZEB1 expression was further increased in the peritoneal disseminated cancer tissues (Fig. 9c).

\section{Discussion}

Scirrhous gastric cancer is one of the most retractable of all cancers. It develops even in younger individuals, such as those in their 20s, and the overall 5-year survival rates of the cancer are remarkably poor (approx. under $7 \%)$. In particular, the property of peritoneal dissemination in scirrhous gastric cancers often torments patients, finally driving them to death [33], and few effective therapies are currently established. In the present study, we found that elevated HOTAIR, which belongs to the lncRNAs, is closely associated with the peritoneal dissemination of scirrhous gastric cancers. Thus, in 60 As 6 cells, our highly metastatic line derived from a patient, the expression of HOTAIR was significantly increased (Fig. 1) compared with that in the parental line with low metastatic properties (HSC-60). We also demonstrated using the patient clinical samples that the HOTAIR expression was significantly higher in primary cancer tissues from patients with peritoneal metastasis than in the cancer tissues from patients without peritoneal metastasis (Fig. 9). The HOTAIR expression was further increased in the peritoneal cancer tissues (Fig. 9). These findings are im- 
Fig. 8. Antiperitoneal dissemination therapy with siRNA-based medicines targeting HOTAIR. a The 60As6 cells without any vectors, such as shRNA vector or overexpression vector, were orthotopically inoculated. Fifteen days later, various siRNAbased therapeutics (control siRNA or HOTAIR siRNA) complexed with atelocollagen were injected into the tumorbearing mice (on days 0,1 , and 2 as indicated in the figure). The set of 3 intravenous injections was repeated on each of days 10,11 , and 12 . Fifteen mice were used to examine each therapeutic. On day 15 , all mice were sacrificed, the primary tumors were excised, and each total RNA was isolated. b, c RT-qPCR for HOTAIR, miR217, ZEB1, E-cadherin, N-cadherin, and vimentin. The results are means \pm SD $(n=$ 15 mice). ${ }^{* * *} p<0.001 ;{ }^{* *} p<0.01$. Lane 1 , control siRNA; lane 2, HOTAIR siRNA. d Ascites volume in the mice. The results are means $\pm \mathrm{SD}(n=15$ mice $) .{ }^{* *} p<0.01$. Lane 1, control siRNA; lane 2, HOTAIR siRNA. e Examination of peritoneal dissemination in the mice.

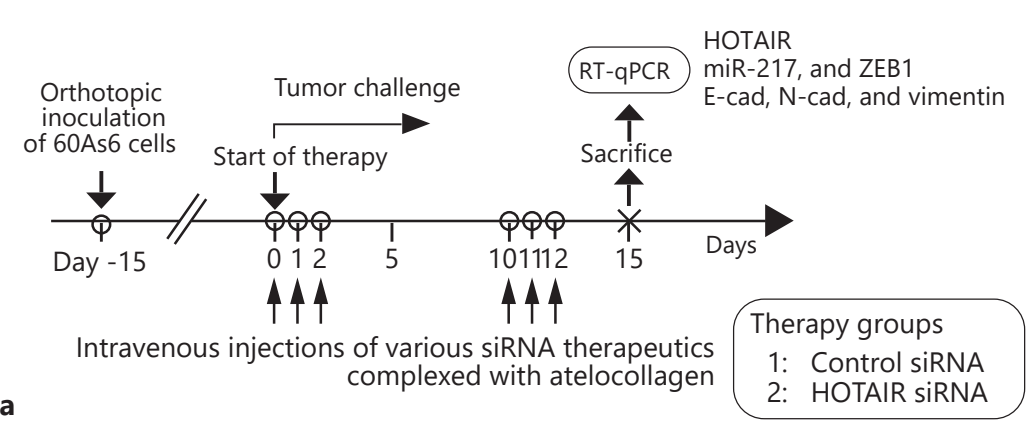

a

$\operatorname{miR}-217$

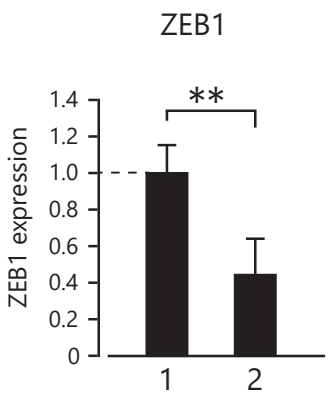

b
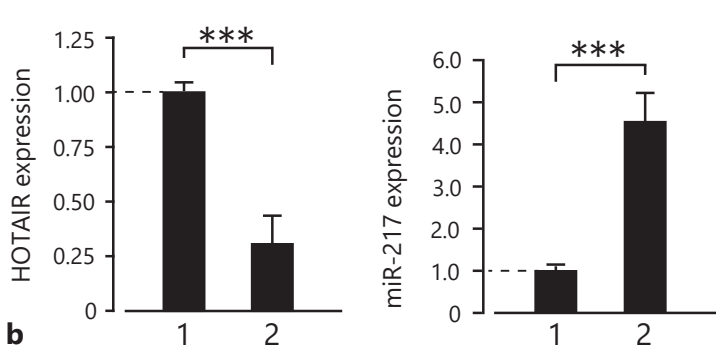

E-cadherin

$\mathrm{N}$-cadherin

Vimentin
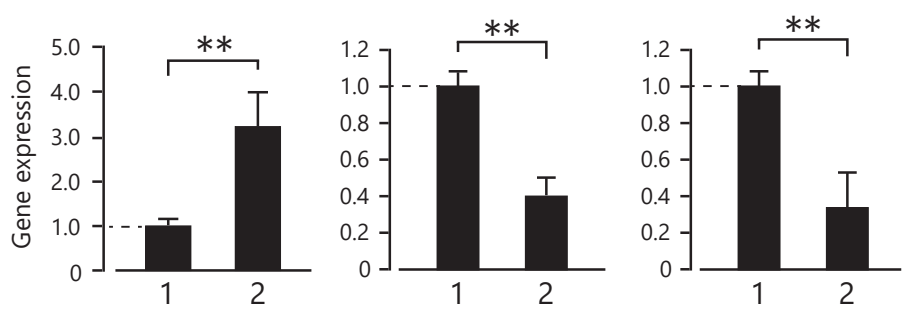

C

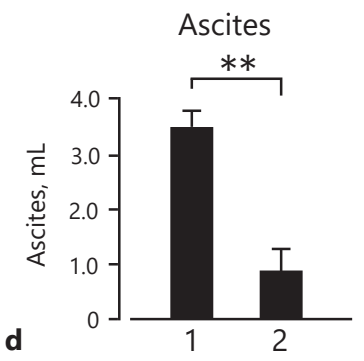

\begin{tabular}{ccc}
\hline \multirow{2}{*}{$\begin{array}{c}\text { siRNA-based } \\
\text { therapeutics }\end{array}$} & \multicolumn{2}{c}{ Disseminated metastasis } \\
\cline { 2 - 3 } & Omentum & Mesenterium \\
\hline Control siRNA & $15 / 15$ & $13 / 15$ \\
HOTAIR siRNA & $5 / 15$ & $4 / 15$ \\
\hline
\end{tabular}

e portant in 2 ways. (i) They suggest that HOTAIR expression could feasibly be used to clinically diagnose peritoneal metastasis of scirrhous gastric cancers. (ii) They suggest that HOTAIR can be targeted to inhibit peritoneal metastasis of scirrhous gastric cancers (opening the possibility of a novel antiperitoneal dissemination therapy).

Other detailed results of these experiments are also noteworthy. Elevated HOTAIR in 60As6 contributes to the promotion of EMT (Fig. 2-4), and the signals of elevated
HOTAIR are transduced to downregulate the miR-217 level and further to dysregulate ZEB1 expression (as a result, upregulation of ZEB1; Fig. 5-7). That upregulation of ZEB1 promotes EMT and cancer metastasis is well known [22, 28-30]. In our in vivo study, we obtained 2 excellent results as follows. (i) When the 60As6-HOTAIR shRNA line (stably expressed line) was orthotopically inoculated into the stomach wall in nude mice, we observed an inhibition of peritoneal dissemination and prolonged survival rate (Ta- 
Fig. 9. Expression levels of HOTAIR (a), miR-217 (b), and ZEB1 (c) in clinical samples from gastric cancer patients. Each sample category (from 1 to 4 ) is shown in the figure. RT-qPCR of each clinical sample was performed. The numbers of samples are also shown. ${ }^{* *} p<0.01 ;{ }^{*} p<0.05$. ns, not significant.

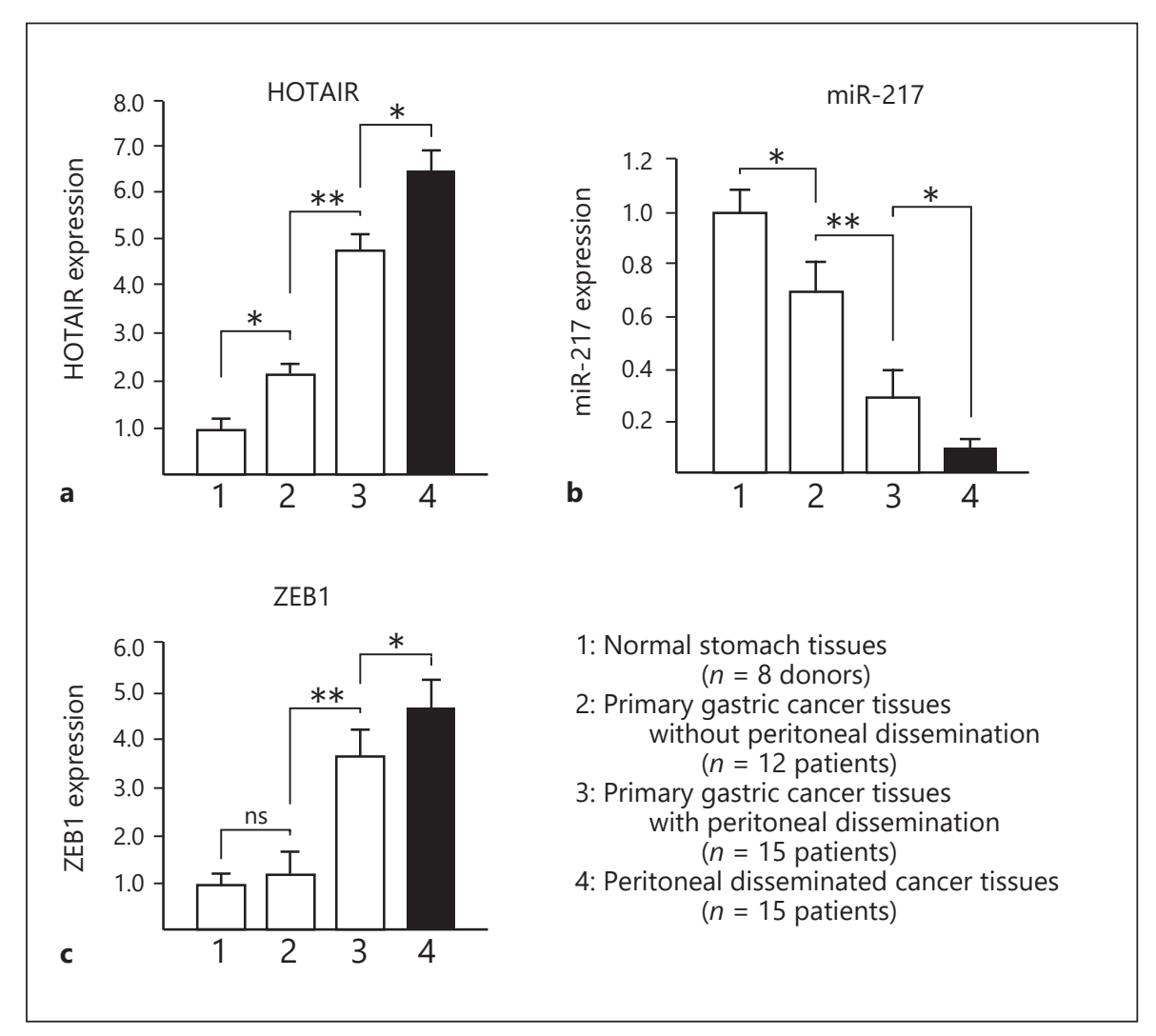

bles 1,2$)$. (ii) In tumor-bearing mice with orthotopic inoculation of 60 As 6 without any transfection of the shRNA, when we intravenously injected the complex of siRNA targeting HOTAIR and atelocollagen, a marked antiperitoneal dissemination effect was shown (Fig. 8). In the treated mice, the HOTAIR expression was reduced to increase miR-217, and to decrease ZEB1 (Fig. 8), as observed in the in vitro study. Further, HOTAIR knockdown in the mice led to a reversal of the EMT status (Fig. 8). We also showed that the overall survival rate of the treated mice was significantly longer ( $73 \pm 13$ days) than that of the control mice (36 \pm 9 days), as shown in Table 3 .

Using another cell line pair (a parental line, HSC44PE, and a metastatic line, 44As3) established from the other patient with human scirrhous gastric cancer, we successfully showed the universality of our findings regarding HOTAIR and EMT (online suppl. Fig. 2-4).

Furthermore, we have some interesting results as follows: we have examined another metastatic line (58As9) that was originally derived from the other patient with scirrhous gastric cancer $[20,21]$. The parental line of 58As9 is HSC-58 [20, 21]. The metastatic line, 58As9, showed a higher level of EMT due to downregulation of the miR-200 fam- ily compared with HSC-58 [22]. The miR-200 family members directly target ZEB1, which is a trigger of EMT [22, 28-30]. Although HOTAIR expression in the 58As9 (metastatic) cells was significantly higher [Takei et al., unpubl. results] than that in the HSC-58 (parental) cells, the difference in HOTAIR expression between HSC-60 and 60As6 cells in the present study (Fig. 1) was even more pronounced. From these results, we conclude that EMT is promoted by at least 2 separate mechanisms in scirrhous gastric cancers: (i) via HOTAIR upregulation (60As6 and 44As3) and (ii) via miR-200 family downregulation (58As9). Both mechanisms then act together to upregulate ZEB1 expression and thereby confer mesenchymal properties onto the cells. Taking all these findings into account, a personalized medicine specifically designed to inhibit peritoneal dissemination at the individual level should be considered.

Metastasis-initiating cells (MICs) have been reported as a special subpopulation of cancer stem cells in primary tumors [34-36]. MICs actively function in cancer metastasis [34-36]. Based on this property of MICs, our metastatic line 60As6 is regarded as an MIC, a specific cell for peritoneal dissemination (in other words, a peritoneal dissemination-initiating cell). Our recent studies have re- 


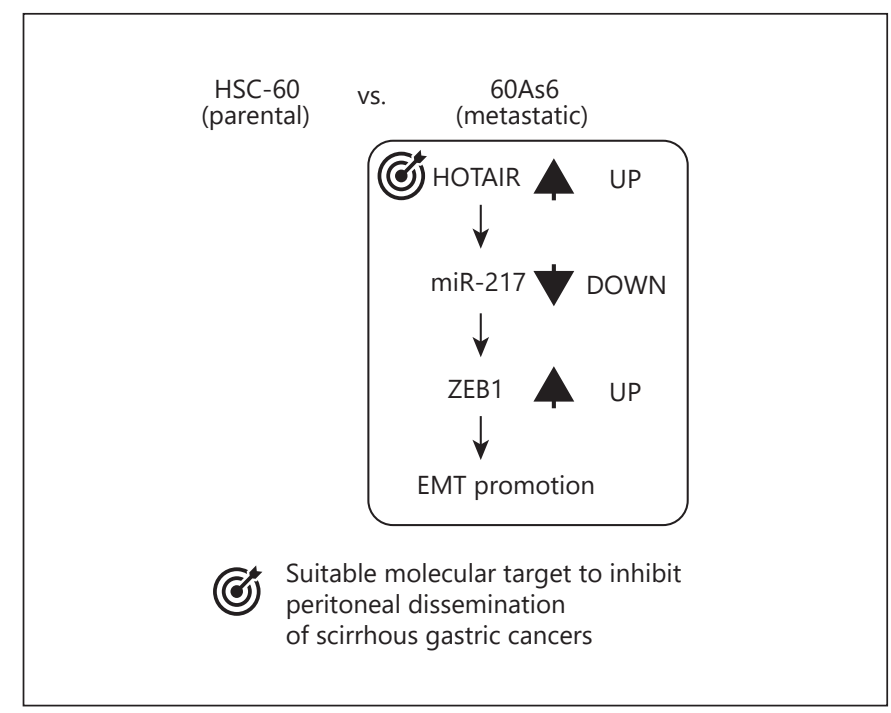

Fig. 10. HOTAIR is a suitable target for the inhibition of peritoneal dissemination in human scirrhous gastric cancers.

vealed the presence of a specific marker protein, CD280, on MICs. Although CD280 is also known as macrophage mannose receptor C type 2 (MRC2), urokinase plasminogen activator receptor-associated protein, or Endo180 protein $[37,38]$, no reports as a marker on MICs appears to date. Details on the results will appear elsewhere.

For the tumor-specific delivery of the siRNA targeting HOTAIR via an intravenous systemic route, we used our original method with the biomaterial known as atelocollagen. Atelocollagen (type I collagen) is derived from the dermis of calves $[39,40]$ and binds with nucleic acid molecules such as siRNA/miRNA via electrostatic interaction to form a complex $[22-27,31,32]$. The complex shows nano-sized particles and maintains siRNA as an intact form in the living body. When intravenously injected into the bloodstream of tumor-bearing mice, the siRNA/atelocollagen complex is accumulated in tumor tissues via an enhanced permeability and retention effect $[41,42]$ and finally penetrates into tumor cells under the mediation of CD280 protein [26]. Here, it is of note that CD280, a transmembrane protein, harbors a collagen-binding site(s) on the extracellular domains $[37,38]$ to facilitate binding of the siRNA/atelocollagen complex. CD280 is overexpressed on the MICs as described above. Taken together, these results show that our siRNA delivery method via atelocollagen is a feasible approach for the specific delivery of siRNA into MICs.

Although many issues must be resolved before practical clinical application is possible, our proposed method of antiperitoneal dissemination therapy targeting HOTAIR and EMT shows great promise as an alternative for patients with scirrhous gastric cancers.

\section{Conclusions}

We demonstrated that high expression of HOTAIR in 60 As6 promotes EMT to assist the peritoneal dissemination of scirrhous gastric cancers. The EMT-associated pathway (HOTAIR-miR-217-ZEB1 axis) might be targeted to inhibit peritoneal dissemination as a novel strategy for the treatment of scirrhous gastric cancers (Fig. 10).

\section{Acknowledgments}

We thank Drs. Kazuo Kita and Takayuki Okubo for their helpful suggestions regarding the experiments. We also thank Ms. Misato Takigahira and Ms. Naomi Maruyama for their excellent technical assistance.

This work was supported in part by Grants-in-Aid for Scientific Research from the Ministry of Education, Culture, Sports, Science and Technology of Japan (17016030) and from the Japan Society for the Promotion of Science $(21590305,24590348,15 \mathrm{k} 15063$, and 16H04697).

\section{Statement of Ethics}

All procedures in this study were in accordance with the ethics standards of the responsible committee on human experimentation (institutional and national) and with the Helsinki Declaration of 1964 and later versions. The Institutional Review Boards on Medical Ethics at Nagoya University School of Medicine, Aichi Gakuin University, and the National Cancer Center Research Institute granted permission for conducting this study.

\section{Disclosure Statement}

There is no conflict of interest to disclose.

\section{References}

1 Rothberg JM, Leamon JH. The development and impact of 454 sequencing. Nat Biotechnol. 2008 Oct;26(10):1117-24.

2 Bahassi M, Stambrook PJ. Next-generation sequencing technologies: breaking the sound barrier of human genetics. Mutagenesis. 2014 Sep;29(5):303-10.

3 Nakagaki T, Tamura M, Kobashi K, Omori A, Koyama R, Idogawa M, et al. Targeted nextgeneration sequencing of 50 cancer-related genes in Japanese patients with oral squamous cell carcinoma. Tumour Biol. 2018 Sep 40(9):1010428318800180. 
4 Xie Y, Dang W, Zhang S, Yue W, Yang L, Zhai $\mathrm{X}$, et al. The role of exosomal noncoding RNAs in cancer. Mol Cancer. 2019 Mar; 18(1):37.

5 Sarfi M, Abbastabar M, Khalili E. Long noncoding RNAs biomarker-based cancer assessment. J Cell Physiol. 2019 Aug;234(10): 16971-86

6 Fernandes JC, Acuña SM, Aoki JI, FloeterWinter LM, Muxel SM. Long non-coding RNAs in the regulation of gene expression: physiology and disease. Noncoding RNA. $2019 \mathrm{Feb} ; 5(1): 17$.

7 Butova R, Vychytilova-Faltejskova P, Souckova $A$, Sevcikova S, Hajek R. Long non-coding RNAs in multiple myeloma. Noncoding RNA. 2019 Jan;5(1):13.

8 Rinn JL, Kertesz M, Wang JK, Squazzo SL, Xu $\mathrm{X}$, Brugmann SA, et al. Functional demarcation of active and silent chromatin domains in human HOX loci by noncoding RNAs. Cell. 2007 Jun;129(7):1311-23.

9 Woo CJ, Kingston RE. HOTAIR lifts noncoding RNAs to new levels. Cell. 2007 Jun;129(7): 1257-9.

10 Khalil AM, Guttman M, Huarte M, Garber M, Raj A, Rivea Morales D, et al. Many human large intergenic noncoding RNAs associate with chromatin-modifying complexes and affect gene expression. Proc Natl Acad Sci USA. 2009 Jul;106(28):11667-72.

11 Gupta RA, Shah N, Wang KC, Kim J, Horlings HM, Wong DJ, et al. Long non-coding RNA HOTAIR reprograms chromatin state to promote cancer metastasis. Nature. 2010 Apr;464(7291):1071-6.

12 Wan Y, Chang HY. HOTAIR: flight of noncoding RNAs in cancer metastasis. Cell Cycle. 2010 Sep;9(17):3391-2.

13 Tang L, Zhang W, Su B, Yu B. Long noncoding RNA HOTAIR is associated with motility, invasion, and metastatic potential of metastatic melanoma. BioMed Res Int. 2013;2013. 251098.

14 Li X, Wu Z, Mei Q, Li X, Guo M, Fu X, et al Long non-coding RNA HOTAIR, a driver of malignancy, predicts negative prognosis and exhibits oncogenic activity in oesophageal squamous cell carcinoma. Br J Cancer. 2013 Oct;109(8):2266-78.

15 Sørensen KP, Thomassen M, Tan Q, Bak M, Cold S, Burton M, et al. Long non-coding RNA HOTAIR is an independent prognostic marker of metastasis in estrogen receptorpositive primary breast cancer. Breast Cancer Res Treat. 2013 Dec;142(3):529-36.

16 Svoboda M, Slyskova J, Schneiderova M, Makovicky P, Bielik L, Levy M, et al. HOTAIR long non-coding RNA is a negative prognostic factor not only in primary tumors, but also in the blood of colorectal cancer patients. Carcinogenesis. 2014 Jul;35(7):1510-5.

17 Qiu JJ, Lin YY, Ye LC, Ding JX, Feng WW, Jin $\mathrm{HY}$, et al. Overexpression of long non-coding RNA HOTAIR predicts poor patient prognosis and promotes tumor metastasis in epithelial ovarian cancer. Gynecol Oncol. 2014 Jul; 134(1):121-8.
18 Li G, Zhang H, Wan X, Yang X, Zhu C, Wang A, et al. Long noncoding RNA plays a key role in metastasis and prognosis of hepatocellular carcinoma. BioMed Res Int. 2014;2014: 780521.

19 Fujita T, Yanagihara K, Takeshita F, Aoyagi $\mathrm{K}$, Nishimura $\mathrm{T}$, Takigahira $\mathrm{M}$, et al. Intraperitoneal delivery of a small interfering RNA targeting NEDD1 prolongs the survival of scirrhous gastric cancer model mice. Cancer Sci. 2013 Feb;104(2):214-22.

20 Yanagihara K, Tanaka H, Takigahira M, Ino Y, Yamaguchi Y, Toge T, et al. Establishment of two cell lines from human gastric scirrhous carcinoma that possess the potential to metastasize spontaneously in nude mice. Cancer Sci. 2004 Jul;95(7):575-82.

21 Yanagihara $\mathrm{K}$, Takigahira $\mathrm{M}$, Tanaka $\mathrm{H}$, Komatsu T, Fukumoto H, Koizumi F, et al. Development and biological analysis of peritoneal metastasis mouse models for human scirrhous stomach cancer. Cancer Sci. 2005 Jun;96(6):323-32.

22 Takei Y, Shen G, Morita-Kondo A, Hara T, Mihara K, Yanagihara K. MicroRNAs associated with epithelial-mesenchymal transition can be targeted to inhibit peritoneal dissemination of human scirrhous gastric cancers. Pathobiology. 2018;85(4):232-46.

23 Takei Y, Suzuki A, Mihara K, Yanagihara K. The microRNA miR-516a-3p regulates the Wnt pathway by targeting extracellular sulfatase 1 in human scirrhous gastric cancers: anti-metastatic therapy via miRNA-based medicine. Med Res Arch. 2017;5(7):1-19.

24 Takei Y, Takigahira M, Mihara K, Tarumi Y, Yanagihara K. The metastasis-associated microRNA miR-516a-3p is a novel therapeutic target for inhibiting peritoneal dissemination of human scirrhous gastric cancer. Cancer Res. 2011 Feb;71(4):1442-53.

25 Takei Y, Yuan Y, Suzuki A, Mihara K. Combined anti-metastasis therapy of an siRNAbased medicine and ABT-263 in orthotopically xenografted prostate cancer model mice. Med Res Arch. 2018;6:1-10.

26 Yuan Y, Makita N, Cao D, Mihara K, Kadomatsu K, Takei Y. Atelocollagen-mediated intravenous siRNA delivery specific to tumor tissues orthotopically xenografted in prostates of nude mice and its anticancer effects. Nucleic Acid Ther. 2015 Apr;25(2):85-94

$27 \mathrm{Mu} \mathrm{P}$, Nagahara S, Makita N, Tarumi Y, Kadomatsu K, Takei Y. Systemic delivery of siRNA specific to tumor mediated by atelocollagen: combined therapy using siRNA targeting $\mathrm{Bcl}-\mathrm{xL}$ and cisplatin against prostate cancer. Int J Cancer. 2009 Dec;125(12):2978-90.

28 Okugawa Y, Toiyama Y, Tanaka K, Matsusita K, Fujikawa H, Saigusa S, et al. Clinical significance of Zinc finger E-box Binding homeobox 1 (ZEB1) in human gastric cancer. J Surg Oncol. 2012 Sep;106(3):280-5.
29 Yabusaki N, Yamada S, Murai T, Kanda M, Kobayashi D, Tanaka C, et al. Clinical significance of zinc-finger E-box binding homeobox 1 mRNA levels in peritoneal washing for gastric cancer. Mol Clin Oncol. 2015 Mar;3(2): $435-41$.

30 Murai T, Yamada S, Fuchs BC, Fujii T, Nakayama G, Sugimoto H, et al. Epithelial-tomesenchymal transition predicts prognosis in clinical gastric cancer. J Surg Oncol. 2014 Jun; 109(7):684-9.

31 Fujimoto I, Takei Y. Atelocollagen-mediated siRNA delivery: future promise for therapeutic application. Ther Deliv. 2014 Apr;5(4): 369-71.

32 Inaba S, Nagahara S, Makita N, Tarumi Y, Ishimoto T, Matsuo S, et al. Atelocollagenmediated systemic delivery prevents immunostimulatory adverse effects of siRNA in mammals. Mol Ther. 2012 Feb;20(2):356-66.

33 Nakamura R, Saikawa Y, Wada N, Yoshida M, Kubota T, Kumai K, et al. Retrospective analysis of prognosis for scirrhous-type gastric cancer: one institution's experience. Int J Clin Oncol. 2007 Aug;12(4):291-4.

34 Notle SM, Singh SK. Origins of metastasisinitiating cells. In: Srivastava R, Shankar S, editors. Stem Cells and Human Diseases. Springer: Netherlands. Vol 11, 2012. p 22946.

35 Kelly K, Yin JJ. Prostate cancer and metastasis initiating stem cells. Cell Res. 2008 May; 18(5): 528-37.

36 Baccelli I, Trumpp A. The evolving concept of cancer and metastasis stem cells. J Cell Biol. 2012 Aug; 198(3):281-93.

37 Sheikh $\mathrm{H}$, Yarwood H, Ashworth A, Isacke CM. Endo180, an endocytic recycling glycoprotein related to the macrophage mannose receptor is expressed on fibroblasts, endothelial cells and macrophages and functions as a lectin receptor. J Cell Sci. 2000 Mar;113(Pt 6): 1021-32.

38 Wienke D, MacFadyen JR, Isacke CM. Identification and characterization of the endocytic transmembrane glycoprotein Endo180 as a novel collagen receptor. Mol Biol Cell. 2003 Sep;14(9):3592-604.

39 Ochiya T, Takahama Y, Nagahara S, Sumita Y, Hisada A, Itoh $\mathrm{H}$, et al. New delivery system for plasmid DNA in vivo using atelocollagen as a carrier material: the Minipellet. Nat Med. 1999 Jun;5(6):707-10.

40 Ochiya T, Nagahara S, Sano A, Itoh $\mathrm{H}$, Terada $\mathrm{M}$. Biomaterials for gene delivery: atelocollagen-mediated controlled release of molecular medicines. Curr Gene Ther. 2001 May;1(1): $31-52$.

41 Maeda H. Research spotlight: emergence of EPR effect theory and development of clinical applications for cancer therapy. Ther Deliv. 2014 Jun;5(6):627-30.

42 Maeda H, Wu J, Sawa T, Matsumura Y, Hori $\mathrm{K}$. Tumor vascular permeability and the EPR effect in macromolecular therapeutics: a review. J Control Release. 2000 Mar;65(1-2): 271-84 